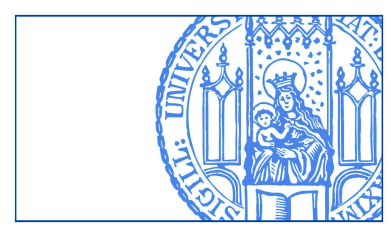

Schlicht, Ekkehart:

Directed Technical Change and Capital Deepening: A Reconsideration of Kaldor's Technical Progress Function

Munich Discussion Paper No. 2014-

Department of Economics

University of Munich

Volkswirtschaftliche Fakultät

Ludwig-Maximilians-Universität München

Online at https://doi.org/10.5282/ubm/epub.20959 


\title{
Directed Technical Change and Capital Deepening: A Reconsideration of Kaldor's Technical Progress Function ${ }^{*}$
}

\author{
Ekkehart Schlicht ${ }^{\dagger}$
}

\begin{abstract}
This note proposes a growth model that is derived from the standard Solow growth model by replacing the neoclassical production function with Kaldor's technical progress function while maintaining a marginalist theory of factor prices in the spirit suggested by von Weizsäcker $(1966,1966 \mathrm{~b})$. The hybrid model so obtained explains balanced growth in a way that appears less arbitrary than the Solow model, especially because it directly accounts for Harrod neutral technical change, without any need for further assumptions. It complements the current neoclassical and AK models by offering a further perspective for interpreting economic growth.

Keywords: directed technical change, directed technological change, bias in innovation, technical progress function, neoclassical production function, Harrod neutrality, Hicks neutrality, Cambridge theory of distribution, marginal productivity theory, Kaldor, Kennedy, von Weizsäcker, Solow model

Journal of Economic Literature Classification: O30, O40, E12, E13, E25, B122, $\mathrm{B}_{31}, \mathrm{~B}_{59}$
\end{abstract}

${ }^{\star}$ This version: June 3, 2014. Comments and suggestions are welcome and may be left at http: //eschlicht.blogspot.de/2014/03/directed-technical-change-and-capital.html.

${ }^{\dagger}$ Professor emeritus of Economics, Department of Economics, Ludwig-Maximilians-Universität München, Germany. Mailing address: Hurtenstr. 13, 82346 Andechs, Germany, email: ekkehart. schlicht@econ.lmu.de. 


\section{Introduction}

The theory of directed technical change, dating back to von Weizsäcker (1962/2010, 1966a) and Kennedy (1964), has recently received renewed attention (Acemoglu 2003, 2009, Ch. 15, Irmen 2013). The basic argument is that factor prices influence the direction of innovations along an innovation possibilities frontier. This note is intended to suggest an alternative mechanism for explaining the direction of technical change. It is based on Nicholas Kaldor's (1957) "technical progress function," according to which the direction of technical change is determined by the rate of capital deepening.

Kaldor's technical progress function is a component of Kaldor's growth theory. As a severe flaw in this theory has been identified in von Weizsäcker $(1966,1966 \mathrm{~b})$, it fell into oblivion and is disregarded in modern expositions. ${ }^{1}$ Yet the technical progress function is independent of the Cambridge theory of distribution against which von Weizsäcker's argument was directed. It can be transplanted into a standard growth model as a replacement of the neoclassical production function. The hybrid model so obtained accounts for productivity growth from the outset and generates Harrod-neutrality quite naturally and without necessitating the usual somewhat arbitrary additional assumptions regarding the direction of technical progress.

The next section outlines the hybrid model. Section 3 discusses some empirical aspects and modeling questions and offers a digression on the general problem of modeling investment in growth models. Section 4 concludes.

\section{A Hybrid Model ${ }^{2}$}

\subsection{The Technical Progress Function}

Consider a closed economy with two factors of production, labor $N$ and capital $K$. Denote output by $Y$ and labor productivity by $y=\frac{Y}{N}$. The development of labor productivity over time depends on the amount of capital employed per worker, denoted by $k=\frac{K}{N}$. The more the capital-labor ratio increases, the more will labor productivity increase, but even without any such capital deepening, labor

\footnotetext{
1 Leading modern textbooks such as Blanchard and Fischer (1989), Romer (2011), Aghion and Howitt (2009) or Acemoglu (2009) do not mention it.

2 I take the term "hybrid model" from Marglin (1987) who used it for a number of different models. The present model may be added to his list. This section draws on the first sections of Schlicht (1974).
} 
productivity will increase somewhat. As Kaldor $(1957,596)$ put it, "some increases in productivity would take place even if capital per man remained constant over time, since there are always some innovations - improvements in factory lay-out and organization, for example - which enable production to be increased without additional investment".

The "technical progress function" formalizes these ideas. It gives the growth rate of labor productivity as an increasing function of capital deepening. Denoting time derivatives by a dot and growth rates by a hat, the growth rate of labor productivity is $\hat{y}=\frac{\dot{y}}{y}=\frac{1}{y} \frac{d y}{d t}$ and the rate of capital deepening is $\hat{k}=\left(\frac{\hat{K}}{N}\right)=\hat{K}-\hat{N}$. The technical progress function gives $\hat{y}$ as a function of $\hat{k}$ :

$$
\hat{y}=\varphi(\hat{k}) .
$$

For $\hat{k}=0$ (a constant capital-labor ratio), the increase in labor productivity is positive, and it is increasing in capital deepening, but these increases are subject to diminishing returns. As Kaldor $(1957,596)$ explains, "there is likely to be some maximum beyond which the rate of growth in productivity could not be raised, however fast capital is being accumulated." Hence the technical progress function "is likely to be convex upwards and flatten out altogether beyond a certain point." These assumptions are formalized for the present purposes as follows:

$$
\varphi(0)>0, \varphi^{\prime}>0, \varphi^{\prime \prime}<0, \varphi^{\prime}(\infty)=0 \text {. }
$$

The technical progress function is depicted in Figure 1. It embodies the idea that capital accumulation and technical progress occur jointly. The idea has been taken up (and acknowledged) by Arrow (1962). It re-surfaced in some more recent AK theories, often in truncated form, namely that "aggregate productivity depends upon the aggregate capital stock" (Aghion and Howitt, 2009, 53). In contrast, Kaldor assumes that even without capital accumulation, productivity increases over time. This is is known as the "Horndal effect" and appears to be an empirical regularity (Lundberg 1961, Ohlin 1962, Lazonick and Brush 1985). Further, the technical progress function is assumed to be convex $\left(\varphi^{\prime \prime}<0\right)$. If it were linear, it could be integrated and into a Cobb-Douglas production function (Hahn and Matthews, 1964, 849). But the Cobb-Douglas production technology seems to be ruled out by empirical findings (Antras, 2004). So convexity appears to be an economically sensible assumption that has apparently obtained some empirical support (Bairam, 1995). Note, however, that a convex technical progress function cannot be integrated into a neoclassical production function (Hahn and Matthews, 


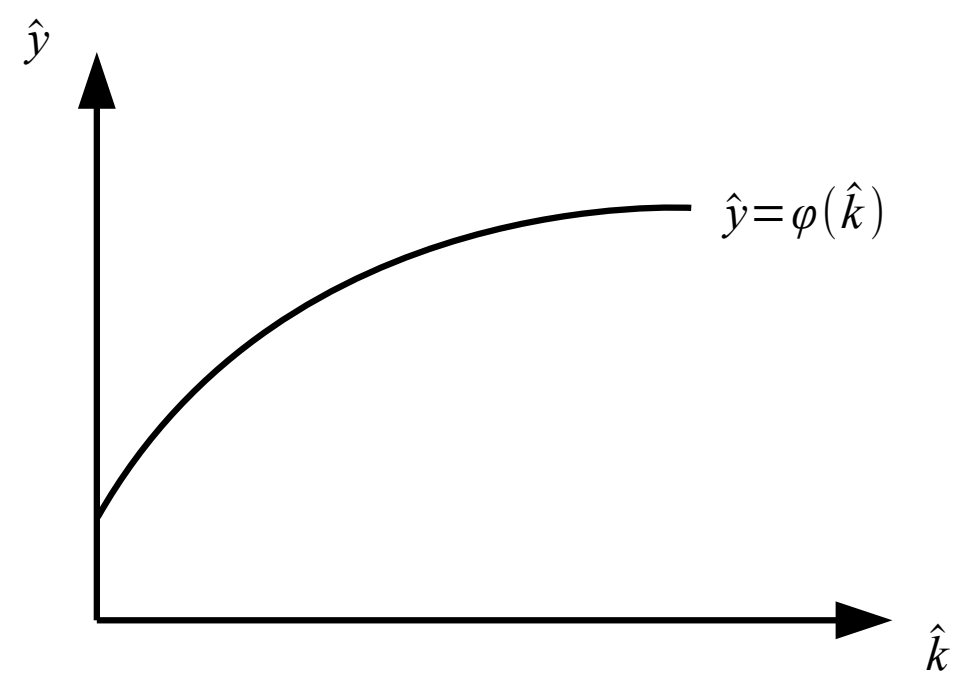

Figure 1: The technical progress function $\varphi$ gives the increase in labor productivity $\hat{y}$ as a function of capital deepening $\hat{k}$.

1964, 849). So it should be possible, in principle, to empirically check which view fits the facts better. Unfortunately, and to the best of my knowledge, this has never been tried.

Given labor productivity $y>0$ and capital productivity $x>0$, production can now be described by a Leontief production function

$$
Y=\min \{y N, x K\}
$$

Both productivities, $x$ and $y$, will vary over time, and the technical progress function can be employed to describe these changes within an otherwise standard growth framework.

Assume that labor grows with a rate $v \geq 0$, the savings rate $s$ is constant and positive $(s>0)$, and the rate of depreciation $\delta$ is constant and positive as well $(\delta>0)$. Full employment of labor and capital implies $y N=x K=Y$. We start from such a situation. With a savings rate $s$, savings are $S=s Y$ and the change in the capital stock is savings $S$ minus depreciation $\delta K$.

$$
\dot{K}=s Y-\delta K .
$$

Dividing this by $K$ and noting $Y=x K$, yields

$$
\hat{K}=s x-\delta .
$$


From this we obtain the rate of capital deepening $\hat{k}$ as

$$
\hat{k}=s x-\delta-v
$$

which is the Solow equation, or accumulation equation, encountered in the standard growth model (Solow, 1956, eq. 6). It gives the rate of capital deepening as a function of the output-capital ratio.

By definition, capital productivity $x$ (the output-capital ratio) is $x=\frac{Y}{K}=\frac{y}{k}$ and its growth rate is

$$
\hat{x}=\hat{y}-\hat{k} \text {. }
$$

The technical progress function (1) gives the increase in labor productivity as a function of the rate of capital deepening. Hence the growth of capital productivity can be written as a function of the rate of capital deepening as well:

$$
\hat{x}=\varphi(\hat{k})-\hat{k}
$$

Since the accumulation equation (4) gives the rate of capital deepening as a function of the output-capital ratio, we obtain finally

$$
\hat{x}=\varphi(s x-\delta-v)-(s x-\delta-v) .
$$

This is a first-order autonomous differential equation that describes the development of capital productivity $x$ over time. It can be analyzed easily.

Without capital deepening capital productivity is $x=\frac{1}{s}(\delta+v)$. Hence capital productivity grows at the rate $\hat{x}=\varphi(0)$ which is positive. On the other hand, for a sufficiently high rate of capital deepening, the technical progress function flattens out $\left(\lim _{\hat{k} \rightarrow \infty} \varphi^{\prime}(\hat{k})=0\right)$. The difference $\varphi(\hat{k})-\hat{k}$ is dominated by the second term and becomes negative $\left(\lim _{\hat{k} \rightarrow \infty}\{\varphi(\hat{k})-\hat{k}\}<0\right)$. In the context of equation $(7)$ this translates into $\lim _{x \rightarrow \infty}\{\hat{x}\}<0$. For continuity reasons there must exist a rate of capital deepening $\gamma$, implicitly defined by

$$
\varphi(\gamma)=\gamma
$$

that generates a constant output-capital ratio. As the second derivative $\frac{d^{2}}{d \gamma^{2}}(\varphi(\gamma)-\gamma)=\varphi^{\prime \prime}$ is negative, the expression $(\varphi(\hat{k})-\hat{k})(k-\gamma)$ is negative definite, and the root is unique.

With a rate of capital deepening of $\gamma$, equation (4) implies a output-capital ratio

$$
\bar{x}=\frac{1}{s}(\gamma+\delta+v)
$$




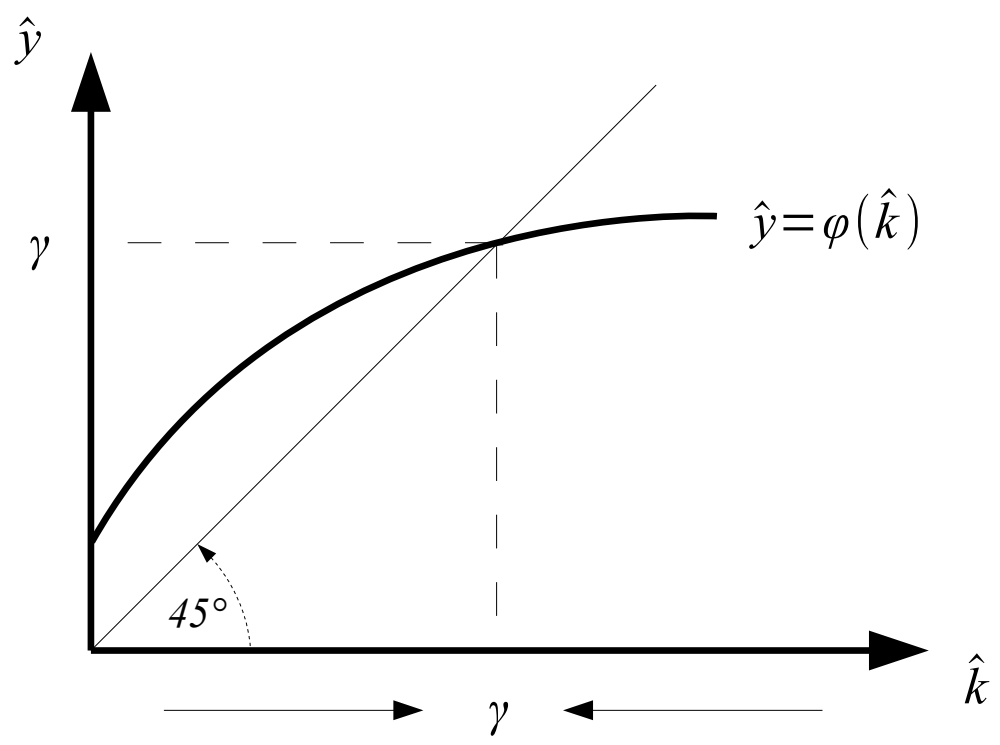

Figure 2: Capital deepening changes over time according to the difference between the change in labor productivity $\hat{y}=\varphi(\hat{k})$ and the rate of capital deepening $\hat{k}$. For values of $\hat{k}$ below $\gamma, \hat{k}$ increases and for values of $\hat{k}$ above $\gamma, \hat{k}$ decreases. The equilibrium at $\hat{k}=\gamma$ is stable.

At this capital-output ratio we have $\hat{x}=0$; so $\bar{x}$ is an equilibrium (critical point) of our differential equation ( 7 ). If the rate of capital deepening is $\gamma$, the outputcapital ratio is such that the rate of capital deepening is equal to $\gamma$; further the output-capital ratio will remain constant at $x=\bar{x}$ over time.

Because $(\varphi(s x-\delta-v)-(s x-\delta-v))(x-\bar{x})$ is negative definite, the equilibrium $\bar{x}$ is globally stable (in the sense of being asymptotically stable). Given any initial value of $x$, capital productivity will approach this equilibrium value over time. In equilibrium, capital productivity $x$ will remain at $x=\bar{x}$ and labor productivity will increase by $\hat{y}=\gamma$. This is illustrated in Figure 2

\subsection{The Direction of Technical Change}

It is interesting to discuss the previous analysis within a standard framework, even if this does not do full justice to Kaldor's ideas.

Looking at the production function (2), $\hat{x}$ can be interpreted as the rate of capital augmenting technical change and $\hat{y}$ can be interpreted as the rate of labor augmenting technical change. The difference $\hat{y}-\hat{x}$ is the Hicksian bias in technical 
progress and $\hat{x}$ is the Harrod bias - it gives the deviation from Harrod neutral technical progress $(\hat{x}=0)$, either capital augmenting $(\hat{x}>0)$ or capital reducing $(\hat{x}<0)$. From $(5)$ it can be seen that the Hicksian bias equals the rate of capital deepening and the Harrod bias is a function of capital deepening. In particular, for $\hat{k}<\gamma$, technical progress is capital augmenting and for $\hat{k}>\gamma$ it is capital reducing. In this sense, the rate of capital deepening determines the direction of technical change.

If we follow Kaldor and assume that the rate of capital deepening is determined by the supply of savings in relation to population growth, the outcome will always tend to Harrod neutral technical change. In this sense, the technical progress function, embedded in a neoclassical framework, offers an alternative mechanism for generating Harrod-neutral technical change.

\subsection{Factor Prices and the Choice of Technique}

While the equilibrium discussed in Section 1 has been derived without reference to factor prices (the wage rate and the rate of interest), this does not imply that factor prices are irrelevant for equilibrium. Rather, any equilibrium must be compatible with cost minimization, and this implies specific factor prices. A simple way to discuss this in the hybrid model is obtained by importing Kennedy's and von Weizsäcker's reasoning about cost minimization and assume that a firm that faces a choice between capital widening and capital deepening will try to settle for a combination of both that maximizes the decline in unit costs. ${ }^{3}$

The technical progress function implies that the firms have a choice between capital widening and capital deepening, and this will affect their costs. A certain amount of money can be invested in order to increase the number of workplaces while keeping the amount of capital invested in each workplace constant. This would be the case of pure capital widening. The capital-labor ratio would be left unchanged, and technical change would be Hicks-neutral. The other possibility is to invest into the existing workplaces in order to make them more productive. This would amount to capital deepening. Depending on the rate of capital deepening,

3 This kind of cost minimization may be termed "gradient cost minimization", as opposed to "present value cost minimization," i.e. the minimization of the present value of total costs. It has been proposed by Kennedy (1964) and von Weizsäcker (1962/2010) and is employed here mainly because of its simplicity and transparency, but also because it carries an intuitive appeal, as competition may be envisaged as a gradient process. For completeness, Appendix 1 gives the solution to the problem of present value cost minimization, and it is shown that gradient cost minimization and present value cost minimization are equivalent in equilibrium but differ somewhat outside equilibrium. 
the direction of technical change may turn out as capital augmenting $(\hat{k}<\gamma)$, Harrod-neutral $(\hat{k}=\gamma)$, or capital reducing $(\hat{k}>\gamma)$. The individual firm faces, thus, a trade-off between the rates of labor and capital augmentation. ${ }^{4}$

Unit costs $z$ are the sum of labor cost and capital user costs per unit. Denote the real wage rate by $w$, the real rate of interest by $r$ and the rate of capital depreciation by $\delta$. These are taken by the firm as exogenously given. Hence labor costs per unit are $\frac{w}{y}$ and capital user costs per unit are $\frac{r+\delta}{x}$. Unit costs are the sum of these:

$$
z=\frac{w}{y}+\frac{r+\delta}{x}
$$

For a constant rate of depreciation, the change of unit costs over time is

$$
\dot{z}=-\frac{w}{y} \hat{y}-\frac{r+\delta}{x} \hat{x}-\frac{\dot{w}}{y}-\frac{\dot{r}}{x} .
$$

In view of equations (1) and (6), the change in unit costs over time is then determined by the rate of capital deepening:

$$
\dot{z}=-z \varphi(\hat{k})-\frac{r+\delta}{x} \hat{k}-\frac{\dot{w}}{y}-\frac{\dot{r}}{x} .
$$

The firms take the factor prices, as well as their changes over time, as exogenous and aim to maximize the decline of unit costs over time. This amounts to maximizing the expression $z \varphi(\hat{k})+\frac{r+\delta}{x} \hat{k}$ by selecting an appropriate rate of capital deepening $\hat{k}$ and leads to the first-order condition for a maximum

$$
\varphi^{\prime}(\hat{k})=\frac{r+\delta}{z x} .
$$

The second order condition $-z \varphi^{\prime \prime}(\hat{k})>0$ is satisfied.

With free entry, competition will eliminate pure profits, and unit costs will be equalized to unit price, which is one. Hence we obtain $z=1$ and

$$
\varphi^{\prime}(\hat{k})=\frac{r+\delta}{x}
$$

\footnotetext{
4 This trade-off has been formalized in von Weizsäcker's (1962/2010) "new technical progress function" and Kennedy's (1964) "innovation possibility function". Its inverse is used in Appendix 1. Kennedy himself has noted the connection of the innovation possibility function and Kaldor's technical progress function: "Surprisingly enough ... our innovation possibility function is really a disguised form of Kaldor's famous technical progress function. ... if the technical progress function is known, the innovation possibility function can be derived from it." (Kennedy, 1964, 547n).
} 


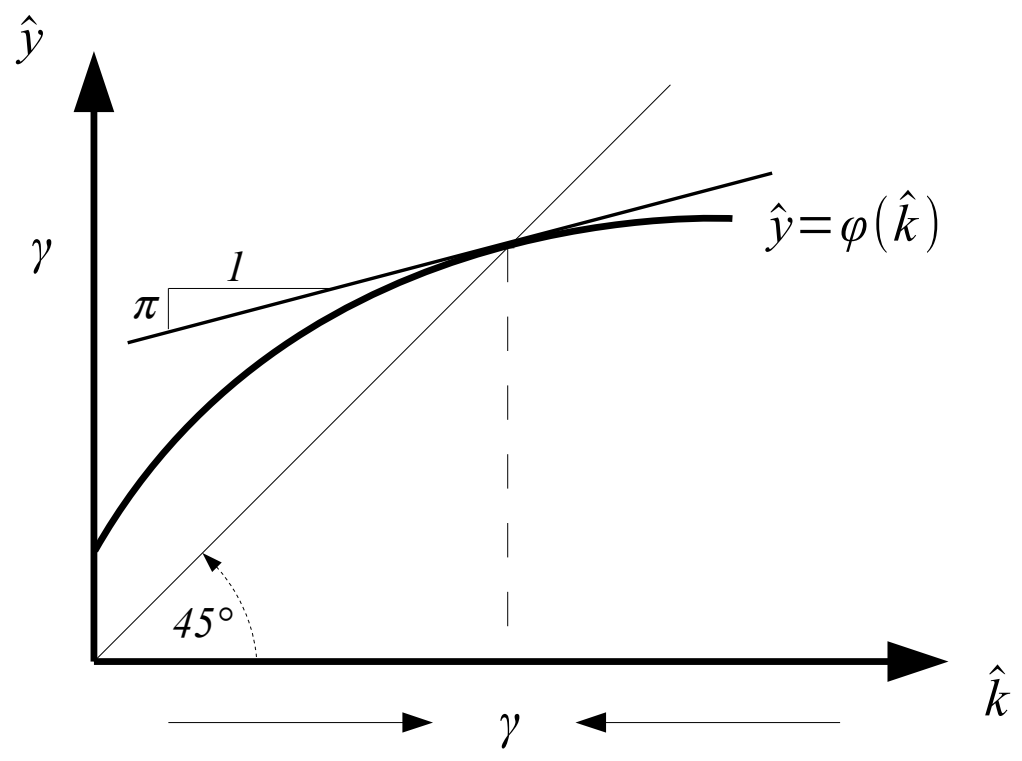

Figure 3: At the stable rate of capital deepening $\hat{k}=\gamma$ the equilibrium profit share $\pi$ equals the slope of the technical progress function $\varphi^{\prime}(\gamma)$.

The expression $\frac{r+\delta}{x}$ gives the share of capital costs in total costs. Equation (11) determines the optimal rate of capital deepening by the condition that the slope of the technical progress function equals the profit share $\pi=\frac{r+\delta}{x}$. This can be written as

$$
\pi=\varphi^{\prime}(\hat{k}) .
$$

This is the condition given by von Weizsäcker $(1962 / 2010,251)$ and Kennedy (1964, 544) for an optimal choice of the direction of technical change in a different guise. ${ }^{5}$

We may think that such choices will be made by different firms. As the technical progress function is assumed to be convex $\left(\varphi^{\prime \prime}<0\right)$, equation (11) tells us that an increase in capital's share will reduce the rate of capital deepening, and an increase in labor's share - the complement to capital's share - will increase the rate of capital deepening selected by each firm. This carries over to the aggregate. In equilibrium, capital's share $\pi$ is given by the slope of the technical progress function at the equilibrium growth rate $\gamma$ (Figure 3 ).

5 As the trade off between capital augmentation $\hat{x}$ and labor augmentation $\hat{y}$ is $\frac{d \hat{x}}{d \hat{y}}=\frac{\varphi^{\prime}-1}{\varphi^{\prime}}$, the optimality condition (11) implies that this trade-off is equal to the ratio of labor's share and capital's share. 
The hybrid growth model can be described by the two equations (7) and (12) which give the system

$$
\begin{aligned}
\hat{x} & =\varphi(s x-\delta-v)-(s x-\delta-v) \\
\pi & =\varphi^{\prime}(s x-\delta-v) .
\end{aligned}
$$

The equation (14) may be further rationalized by considering the following adjustment process. Denote the inverse function of the first derivative of the technical progress function by $\kappa(\cdot)$. This amounts to

$$
\varphi^{\prime}(\kappa(\pi))=\pi
$$

Hence $\kappa(\pi)$ gives the rate of capital deepening desired by the firms if the profit share is $\pi$. As $\varphi^{\prime \prime} \pi^{\prime}=1$ and $\varphi^{\prime \prime}<0$, we have $\kappa^{\prime}<0$. The desired rate of capital deepening is a decreasing function of the profit share. If we postulate that a supply of capital deepening $\hat{k}$ in excess of the desired rate of capital deepening $\kappa(\pi)$ entails an excess supply of capital relative to labor, capital costs will decline and the profit share will be reduced, and we arrive at the adjustment equation

$$
\dot{\pi}=\mu(\hat{k}-\kappa(\pi))
$$

for some speed of adjustment $\mu>0$. As $\frac{\partial \dot{\pi}}{\partial \pi}=-\mu \kappa^{\prime}<0$, a sufficiently high speed of adjustment $\mu$ guarantees that this adjustment to any time path of $\hat{k}$ is stable. ${ }^{6}$

\section{Discussion}

\subsection{Kaldor's Stylized Facts}

Kaldor's (1957) has listed a number of "stylized facts" about economic growth. It is largely accepted that any theory of growth should, as a first approximation, account for these "facts" - it should be able account for balanced growth. The hybrid model (13), (14) does so without the need of additional assumptions:

1. The capital/output ratio remains roughly constant. (Capital productivity $x$ converges to $\bar{x}=\frac{1}{s}(\gamma+\delta+v)$, see (9) and Figure 2.)

6 The function $\phi(x, \pi)=(s x-\gamma-\delta-v)^{2}$ is a Ljapunov function for (13) and the function $\varphi(x, \pi)=(s x-\gamma-\delta-v-\kappa(\pi))^{2}$ is a partial Ljapunov function for (15). Together they satisfy the requirements for the moving equilibrium theorem given in Schlicht $(1985,40)$. Hence the system (13), (15) is globally asymptotically stable. 
2. The profit share remains roughly constant. (As $x$ converges to $\bar{x}$, the profit share converges to $\varphi^{\prime}(\gamma)$, see equation (14). This implies also that labor's share $1-\pi$ remains constant.)

3. The growth of labor productivity remains roughly constant. (It tends to $\gamma$, see Figure 2.)

4. The capital-labor ratio grows at a roughly constant rate. (It grows with $s \bar{x}-\delta-v=\gamma$, see Figure 2.)

5. The rate of return on investment remains roughly constant over time. (Equations (11) and (9) imply an equilibrium rate of interest $r=\frac{1}{s} \varphi^{\prime}(\gamma)(\gamma+\delta+v)-\delta$. $)$

6. The real wage grows over time. (As labor's share $\frac{w}{y}$ remains constant, the real wage $w$ will grow with the same rate as labor productivity $y$; both grow with $\gamma$.

Thus the hybrid model presented here actually implies Kaldor's "facts." This does not rule out that modifications may be introduced to fine-tune the model to other developments; as would always be the case, with any model.

A further "fact" may be added to Kaldor's list and is implied by the hybrid model:

7. The share of profits is less than 50 per cent. (The technical progress function must cut the 45-degree line from above. Its slope at the intersection gives the profit share $\pi$ and must be less than .5, see Figure (3).) This proposition is empirically supported (Giovannoni, 2010).

\subsection{The Neoclassical Twin}

Much insight can be gained by abandoning model monism and interpreting actual growth processes from several perspectives, such as the neoclassical or AK. This as is nicely done in Aghion and Howitt (2009), for example. The hybrid model offers a third perspective that may complement the others for such purposes.

The differences between the three approaches relate mainly to the modeling of production and technological change, because all three approaches don't differ much with regard to consumer behavior: consumers who want to maximize lifetime utility (or something else) are, in a steady state, basically faced with the same data: an exponential growth of the real wage and a fixed rate of interest. Hence their 
intertemporal decisions can always be modeled in the same manner. Regarding issues like convergence between different economies, spillovers, and the long-run determinants of growth, these model differ somewhat, but a detailed discussion of these matters goes beyond the scope of the present paper and must be left to future research.

The central theoretical difference between the hybrid model and both the neoclassical models and the AK models concerns to the direction of technical change. The problems pose themselves in similar ways in the AK models and in the neoclassical models, but the discussion is better developed for the neoclassical case. For this reason, it is perhaps apposite to illustrate this aspect by juxtaposing the hybrid model and an analogous neoclassical model, its "neoclassical twin". This will be done in the following.

The neoclassical twin of the hybrid model is obtained by replacing the Leontief production function (2) by a neoclassical production function. This production function gives output $Y$ as a smoothly differentiable function of labor input $N$ and capital input $K$. In order to account for growth, it must be time-dependent: $Y=F(N, K, t)$. Further, $F(\cdot)$ is assumed to be linear homogeneous in $N$ and $K$. This permits to define the associated per-capita production function $f(\cdot)$ as $f(k, t):=F(1, k, t)$ which gives per-capita production $y$ as a function of capital intensity $k: y=f(k, t)$. As the output-capital ratio is $x=\frac{y}{k}$, we obtain from (4) the Solow model in its standard form.

$$
\dot{k}=s f(k, t)-(v+\delta) k .
$$

For any given initial capital-labor ratio $k_{0}$, equation (16) determines the time paths of the capital-labor ratio $k$ and labor productivity $y$. Although it appears that factor prices do not enter the model (16), this is not quite correct. In any equilibrium, factor prices must be compatible with cost minimization. Given factor prices $w$ and $r$, the firms will determine a cost minimizing technique by selecting a capital intensity that minimizes unit costs $\frac{w+(r+\delta) k}{f(k, t)}$. This implies the marginal productivity theory according to which the profit share equals the production elasticity of capital

$$
\pi=\frac{f^{\prime}(k, t) k}{f(k, t)} .
$$

This corresponds to condition (12) in the hybrid model. Equations (16), (17) define the neoclassical twin of the hybrid model (13), (14). Whereas the hybrid model accounts for Kaldor's stylized facts without ado, this is not true for the neoclassical twin. Indeed, the key dilemma of the neoclassical twin is that it does not imply 
anything. By postulating a suitable shifting of the production function over time, the model can be made compatible with practically all conceivable developments, including developments that conform to Kaldor's stylized facts. In order to obtain time-paths that conform to those "facts," however, it is necessary to assume a very specific shifting of the production function over time: we need to assume Harrod neutral technical change in the relevant range (Schlicht, 2006). The sole justification for this assumption is that it generates time-paths that accommodate Kaldor's facts. By this assumption the model is tweaked to deliver the desired result. The model itself contributes nothing in this regard. Harrod neutrality "is just a special case" (Hahn and Matthews, 1964, 831). As Aghion and Howitt (2009, 28n) put it:

There is no good reason to think that technological change takes [the Harrod neutral] form; it just leads to tractable steady-state results.

More specifically, the production function must be specified as $F(N, K, t)=$ $\Psi\left(e^{\gamma t} N, K\right)$ which translates for the per capita production function to $f(k, t)=$ $e^{\gamma t} \psi\left(e^{-\gamma t} k\right)$. The thus adjusted twin model now reads:

$$
\begin{aligned}
\dot{k}_{t} & =s e^{\gamma t} \psi\left(e^{-\gamma t} k_{t}\right)-(v+\delta) k_{t} \\
\pi_{t} & =\frac{\psi^{\prime}\left(e^{-\gamma t} k_{t}\right) k_{t}}{\psi\left(e^{-\gamma t} k_{t}\right)} .
\end{aligned}
$$

This adjusted model (18), (19) is the only formal solution that generates results fitting Kaldor's "facts." With any production function $f(\cdot)$ that cannot be written as $e^{\gamma t} \psi\left(e^{-\gamma t} k\right)$, the model is incompatible with these "facts."

It is easy to check that the time path

$$
\bar{k}_{t}=e^{\gamma t} \bar{k}_{0}
$$

with $\bar{k}_{0}$ as the root of $\psi\left(\bar{k}_{0}\right)=\frac{1}{s}(v+\delta+\gamma)$ is a solution to (18). This is the balanced growth path. Under the usual assumptions, $\bar{k}_{0}$ is unique and all solutions $k_{t}$ of (18) converge to $k_{t}$ in the sense that the ratio $\frac{k_{t}}{\bar{k}_{t}}$ approaches one for $t \rightarrow \infty{ }^{8}$

\footnotetext{
7 More precisely: with any other production function, equation (18) violates Kaldor's "facts." The underlying theorem is Uzawa's (1961) steady state theorem. It has originally been proved under the assumption that the marginal productivity theory (19) holds true. Schlicht (2006) has shown that the theorem can be generalized and holds true regardless of the theory of distribution employed. In other words, the necessity of Harrod neutrality persists even if equation (19) that embodies the marginal productivity theory is replaced by something else.

8 See Appendix A 2.
} 
Yet the assumption that technical progress takes the very special form $e^{\gamma t} \psi\left(e^{-\gamma t} k\right)$ appears arbitrary. One way out is to assume right away that the production function is Cobb-Douglas, but this conflicts with empirical evidence (Antras, 2004). Another way out has been proposed by Irmen (2013) who shows that capital-augmenting technical progress can be accommodated with Kaldor's "facts" if adjustment costs of capital grow by a rate that happens to just compensate the bias. However, this assumption appears as special as the straightforward assumption of Harrod neutrality. A third, and perhaps more preferable, way to reduce this arbitrariness has been proposed by von Weizsäcker (1962/2010,1966a) and Kennedy (1964). They assume that that factor prices govern the direction of technical change. The more abundant factor will become cheaper and technical progress will be directed towards increasing the efficiency of the scarce factor. This mechanism has been added to the basic neoclassical model by von Weizsäcker (1962/2010), Samuelson (1965), and Drandakis and Phelps (1966) to rationalize Harrod neutrality. (Kennedy (1964) and von Weizsäcker (1966a) employ a Leontief production function.)

The argument is that capital augmenting technical change would make capital increasingly abundant and labor increasingly scarce. Technical change will therefore tend to eventually become Harrod neutral. This argument appears problematic because the assumption of Harrod neutrality is now replaced the "innovation possibility function" that describes the trade off between labor augmenting and capital augmenting technical change. As this trade off at the Harrod-neutral position determines the shares of capital and labor, the trade off is critical but there is again no good reason to assume that this trade-off is roughly stable. Such an assumption would presuppose a knowledge about trade-offs among yet unknown future technologies.

The results "depend on the invariance over time of the innovation possibility functions, an invariance that is ... difficult to swallow" (Kennedy, 1973, 56). It may even be argued that the direct macro assumption of Harrod neutrality is preferable over the trade-off argument because both would appear equally arbitrary, yet the former is more transparent (Schlicht, 2006, n. 1).

Further, the assumption of a neoclassical production function is open to the criticism raised in the capital controversy of the sixties. This is a severe shortcoming that has induced some leading proponents of the neoclassical growth model to turn to Austrian capital theory (von Weizsäcker 1971, Hicks 1973b, 1973a), and others to leave the field (Samuelson 1966). The hybrid theory sidesteps this problem. Kennedy $(1973,53)$ saw this as an advantage of his theory of technical progress (in its multi-sector version): 
... the theory neatly sidesteps all the difficulties that arise when relative prices alter as a result of changes in the rate of interest, difficulties exemplified by the recent concern about re-switching. Since in real life changes in relative prices are brought about much more significantly by technical progress than by changes in the rate of interest, it is reassuring to have a theory in which the rise in the relative price of a factor leads unequivocally to an economy in its use!

This carries over to the hybrid model.

\subsection{The Concept of Capital}

One reason for Kaldor to develop the concept of the technical progress function relates to the concept of capital. He argues that it is not useful to separate investment in physical capital from investment in new technologies, because both usually go together:

... the present model ... eschews any distinction between changes in techniques (and in productivity) which are induced by changes in the supply of capital relative to labor and those induced by technical invention or innovation - i.e., the introduction of new knowledge.

As his reason he gives:

The use of more capital per worker (whether measured in terms of the value of capital at constant prices, in terms of tons of weight of the equipment, mechanical power, etc.) inevitably entails the introduction of superior techniques which require "inventiveness" of some kind, though these need not necessarily represent the application of basically new principles or ideas. On the other hand, most, though not all, technical innovations which are capable of raising the productivity of labor require the use of more capital per man - more elaborate equipment and/or more mechanical power

and he continues:

It follows that any sharp or clear-cut distinction between movements along a "production function" with a given state of knowledge, and a shift in the"production function" caused by a change in the state of knowledge is arbitrary and artificial. Hence instead of assuming 
that some given rate of increase in productivity is attributable to technical progress which is superimposed, so to speak, on the growth of productivity attributable to capital accumulation, we shall postulate a single relationship between the growth of capital and the growth of productivity which incorporates the influence of both factors (Kaldor, 1957, 393f).

As a consequence, the concept of capital must be seen as involving all outlays for investment. The idea is that investment spending is optimally allocated between development of new technology, and the installment of new production facilities. (Such division has been modeled in the early neoclassical endogenous growth models by Conlisk $(1967,1969)$ and Vogt $(1968)$.) This view seems to accord with current business practice, as the price paid for a new machine will cover both R\&D expenditure and production costs for that product. So our statistical data lump these expenses together. From a practical point of view it appears, thus, reasonable to employ Kaldor's concept of capital instead of making a distinction between physical and intellectual capital.

\subsection{Digression: The Missing Investment Function}

The hybrid model is, however, quite unsatisfactory in a different way, and shares this deficiency with the neoclassical model (and the AK models): there is no independent investment function. Rather it is assumed that the consumers' savings decision automatically translate into investment. Yet in a decentralized economy, saving decisions are made by households, while investment decisions are made by firms. So these decisions are made independently of each other, and it is necessary to postulate a mechanism that equates savings with investment.

Regarding the neo-classical model, Hahn and Matthews $(1964,790)$ remark on that problem:

In its basic form the neo-classical model depends on the assumption that it is always possible and consistent with equilibrium that investment should be undertaken of an amount equal to full-employment savings. The mechanism that ensures this is as a rule not specified.

This assumption leads to severe problems regarding logical consistency, both of the hybrid model and its neo-classical twin. In the following I shall simply outline this problem for both models. As the problem remains unsolved, I cannot offer any solution, but it may become apparent that taking the problem seriously might open interesting theoretical prospects. 
The problem involved here is that, by adding another equation to a fully specified model, the model becomes "overdetermined" in the sense that it contains more equations than unknowns (Sen 1963, Schlicht 1983, Marglin 1987, 14). One solution is to introduce another variable that can assume a value such that the new equation can be made consistent with the initial model by a suitable adjustment of this variable. In this case, the investment function would be inessential and could simply be dropped. Hahn and Matthews $(1964,790)$ have described this approach:

Most neo-classical writers have, however, had in mind some financial mechanism. In the ideal neo-classical world one may think of there being a certain level of the rate of interest $(r)$ that will lead entrepreneurs, weighing interest cost against expected profits, to carry out investment equal to full-employment savings. In the absence of risk, etc., the equilibrium rate of interest would equal the rate of profit on investment; otherwise the rate of profit will be higher by the requisite risk premium.

While such an argument sounds convincing, it is feasible neither for the hybrid model nor its neo-classical twin.

In the hybrid model, the equilibrium rate of interest is determined by the slope condition $\frac{s(r+\delta)}{(\gamma+\delta+v)}=\varphi^{\prime}(\gamma)$ and the equilibrium output capital ratio, see equations (11) and (9). This implies an equilibrium rate of interest

$$
r=\frac{1}{s} \varphi^{\prime}(\gamma)(\gamma+\delta+v)-\delta .
$$

So there is no room for varying the rate of interest such that the volume of investment is adjusted to savings. To achieve this, two rates of interest would be needed: one to induce the correct choice of technique, the other to induce the correct volume of investment.

In the neo-classical twin the problem is similar. The equilibrium rate of interest that induces a cost minimizing choice of capital intensity in equilibrium is fixed as

$$
r=\psi^{\prime}\left(\bar{k}_{0}\right)
$$

with $\bar{k}_{0}$ determined as the root of $\psi\left(\bar{k}_{0}\right)=\frac{1}{s}(v+\delta+\gamma)$. So there is no room for varying the rate of interest in order to adjust investment to savings here, just as in the hybrid model.

Including a risk premium would not change matters, because the capital costs relevant for the choice of technique will be the same as the capital costs relevant 
for determining the level of investment: they are simply capital costs, whether with or without a risk premium. From this point of view, solutions like those proposed by Beckmann (1965, eq. 12), von Weizsäcker (1966, eq. 9), or Fischer (1972, eq. 16) appear problematic.

Kaldor was aware of this problem. He thought that the technical progress function would permit getting rid of the over-determination problem by eliminating marginal productivity theory. This would permit dropping the equations that determine factor prices ((14) in the hybrid model or (19) in the neo-classical twin) and thereby make room for the Cambridge theory of factor prices that builds on the equalization of saving and investment. But this position is not tenable, as von Weizsäcker $(1966,1966$ b) has shown.

The classical assumptions about saving and investment would avoid the overdetermination problem: if the savings rate is equal to the profit share and all profits are re-invested, savings and investment are always equal, and the problem vanishes. Similarly, if the social planner decides about savings and investment simultaneously, the problem disappears. The problem emerges only with an independent investment function.

Yet an independent investment function seems to be required in order to make the argument that savings and investment are adjusted to each other. The assertion that this happens automatically is appropriate for the classical assumptions about savings and investment, or for the planning solution (the Ramsey-Cass-Koopmans models), but inappropriate in a monetary economy where saving decisions and investment decisions are made independently of each other by different actors.

The introduction of an independent investment function may lead to interesting prospects, though. To illustrate, consider the case that the equalization of savings and investment requires a rate of interest $r_{1}$, and that the proper choice of technique requires a different interest rate $r_{2}>r_{1}$. If monetary policy succeeds to establish the interest rate $r_{1}$, the desired rate of capital deepening would be too large. The newly created jobs would be endowed with too much capital, and not enough workplaces can be created with the given amount of investment; unemployment of labor through capital shortage would result. In the converse case $r_{1}>r_{2}$, the rate of capital deepening would be too low, more jobs would be newly created than could be manned, and a labor shortage would result.

Despite these potentially interesting and promising aspects, no systematic theoretical work has taken up these problems as yet and these and related ideas (for instance, the possible role of the business cycle in solving the puzzle as in Schlicht 1983) remain speculation. 


\section{Conclusion}

The present note has been written in order to draw attention to Kaldor's technical progress function and to acknowledge it as a pioneering contribution to endogenous growth that, although largely forgotten, provides an interesting and still relevant alternative to current modeling. The substitution of the neo-classical production function by Kaldor's technical progress function in a standard growth model leads to a hybrid model that provides an interesting alternative to standard growth theory. It accounts for balanced growth without any further assumptions, while the standard growth models need to be tweaked in a way by assumptions that amounts to assuming the result.

Faced with different models of economic growth we ought, I think, refrain from model monism and not insist that one particular model is the correct one and the others are wrong. Rather we should appreciate various different approaches to growth processes in their own right and discuss empirical findings in the light of the alternative interpretations provided. Further, all current approaches to the theory of growth, including the hybrid model presented here, are far from being acceptable as something more than just a point of view because they leave important questions unanswered, as has been illustrated in Section 3.4 about the missing investment function. There remains plenty of work to do.

\section{References}

Acemoglu, D. (2003). Labor- and Capital-Augmenting Technical Change. Journal of the European Economic Association, 1(1): 1-37. URL http://ideas.repec.org/a/tpr/ jeurec/v1y2003i1p1-37.html.

Acemoglu, D. (2009). Introduction to Modern Economic Growth. Princeton and Oxford: Princeton University Press. uRL http://press.princeton.edu/titles/8764. html.

Aghion, P., and Howitt, P. W. (2009). The Economics of Growth. The MIT Press. ISBN 9780262012638. URL http://amazon.com/o/ASIN/0262012634/.

Antras, P. (2004). Is the U.S. Aggregate Production Function Cobb-Douglas? New Estimates of the Elasticity of Substitution. Scholarly articles, Harvard University Department of Economics. URL http://EconPapers.repec.org/RePEc:hrv:faseco: 3196325. 
Arrow, K. J. (1962). The Economic Implications of Learning by Doing. The Review of Economic Studies, 29(3): 155-173. ISSN 00346527. URL http://www.jstor.org/ stable/2295952.

Bairam, E. (1995). Kaldor's technical progress function revisited. Applied Economics Letters, 2(9): 302-304. URL http://ideas.repec.org/a/taf/apeclt/v2y1995i9p302-304. html.

Beckmann, M. (1965). A Wicksellian Model of Growth. Rivista internazionale di scienze economiche e commerciali, xii(3): 201-210. URL http://www.econbiz.de/ Record/a-wicksellian-model-of-growth-beckmann-martin/10001887386.

Blanchard, O. J., and Fischer, S. (1989). Lectures on Macroeconomics. Cambridge, M.A. and London: MIT Press. URL http://amazon.com/o/ASIN/0262022834/.

Conlisk, J. (1967). A Modified Neoclassical Growth Model with Endogenous Technical Change. Southern Economic Journal, 34(2): pp. 199-208. ISSN 00384038. URL http://www.jstor.org/stable/1055037.

Conlisk, J. (1969). A Neoclassical Growth Model with Endogenously Positioned Technical Change Frontier. The Economic Journal, 79(314): pp. 348-362. IssN o0130133. URL http://www.jstor.org/stable/2230173.

Drandakis, E., and Phelps, E. S. (1966). A Model of Induced Invention, Growth, and Distribution. Economic Journal, 76(304): 823-40. URL http://www.jstor.org/ stable/2229086.

Fischer, S. (1972). Keynes-Wicksell and Neoclassical Models of Money and Growth. American Economic Review, 62(5): 880-90. URL http://EconPapers.repec.org/ RePEc:aea:aecrev:v:62:y:1972:i:5:p:880-90.

Giovannoni, O. (2010). Functional Distribution of Income, Inequality and the Incidence of Poverty: Stylized Facts and the Role of Macroeconomic Policy. UTIP Working Paper 58, The University of Texas Inequality Project, LBJ School of Public Affairs, The University of Texas at Austin, Austin TX 78712. URL http://utip.gov.utexas.edu/papers/utip_58.pdf.

Hahn, F. H., and Matthews, R. C. O. (1964). The Theory of Economic Growth: A Survey. The Economic Journal, 74(296): pp. 779-902. ISSN 00130133. URL http://www.jstor.org/stable/2228848. 
Hicks, J. R. (1973a). Capital and Time: A Neo-Austrian Theory. Oxford University Press, USA, first edition. ISBN 9780198281795. URL http://amazon.com/o/ASIN/ 019828179X/.

Hicks, J. R. (1973b). The Mainspring of Economic Growth. Nobel Prize in Economics documents 1972-1, Nobel Prize Committee. URL http://EconPapers.repec. org/RePEc:ris:nobelp:1972_oo1.

Irmen, A. (2013). Adjustment costs in a variant of Uzawa's steady-state growth theorem. Economics Bulletin, 33(4): 2860-2873. URL http://EconPapers.repec.org/ RePEc:ebl:ecbull:eb-13-00654.

Kaldor, N. (1957). A Model of Economic Growth. The Economic Journal, 67(268): 591-624. ISSN 00130133. URL http://www.jstor.org/stable/2227704.

Kennedy, C. (1964). Induced Bias in Innovation and the Theory of Distribution. The Economic Journal, 74(295): 541-547. ISSN 00130133. URL http://www.jstor.org/ stable/2228295.

Kennedy, C. (1973). A Generalisation of the Theory of Induced Bias in Technical Progress. Economic Journal, 83(329): 48-57. URL http://EconPapers.repec.org/ RePEc:ecj:econjl:v:83:y:1973:i:329:p:48-57.

Koopmans, T. C. (1963). On the Concept of Optimal Economic Growth. In Salviucci et al. (Ed.), Study Week on the Econometric Approach to Development Planning, number 163 in Pontificiae Academiae Scientiarum Scripta Varia 28, pages 225-287. Amsterdam and New York: North Holland and Rand McNally. URL http://amazon.com/o/ASIN/BoooRKYWWU. Preprint: http://EconPapers. repec.org/RePEc:cwl:cwldpp:163.

Lazonick, W., and Brush, T. (1985). The horndal effect in early U.S. manufacturing. Explorations in Economic History, 22(1): 53-96. uRL http://ideas.repec.org/a/eee/ exehis/v22y1985i1p53-96.html.

Lundberg, E. (1961). Produktivitet och räntabilitet: studier $i$ kapitalets betydelse inom svenskt näringsliv. Studieförbundet Näringsliv och samhälle. URL http: //books.google.de/books?id=kKydQAAACAAJ.

Marglin, S. A. (1987). Growth, Distribution and Prices (Harvard Economic Studies). Harvard University Press. ISBN 9780674364165. URL http://amazon.com/o/ASIN/ 0674364163/. 
Ohlin, G. (1962). Review of Produktivitet och räntabilitet: Studier i kapitalets betydelse inom svenskt näringsliv by Erik Lundberg. The American Economic Review, 52(4): pp. 827-829. ISSN 00028282. URL http://www.jstor.org/stable/ 1808998.

Romer, D. (2011). Advanced Macroeconomics (McGraw-Hill Series Economics). McGraw-Hill/Irwin, 4 edition. ISBN 9780073511375. URL http://amazon.com/o/ ASIN/0073511374/.

Samuelson, P. A. (1965). A Theory of Induced Innovation along Kennedy-Weisäcker Lines. The Review of Economics and Statistics, 47(4): 343-356. ISSN 00346535. URL http://www.jstor.org/stable/1927763.

Samuelson, P. A. (1966). A Summing Up. The Quarterly Journal of Economics, 8o(4): pp. 568-583. ISSN 00335533. URL http://www.jstor.org/stable/1882916.

Schlicht, E. (1974). The Impact of Some Investment Functions in a Kaldorian Growth Model. Discussion paper 17, Universität Regensburg, Fachbereich Wirtschaftswissenschaft, Regensburg. URL http://epub.ub.uni-muenchen.de/ 14801/. Paper presented at the Winter Symposium of the Econometric Society, Budapest, January 26-28, 1974.

Schlicht, E. (1983). Zwei makroökonomische Koordinationsprobleme. Karl Acham (Hg.): Gesellschaftliche Prozesse, Graz 1983, pages 143-148. uRL http://epub.ub. uni-muenchen.de/14810/.

Schlicht, E. (1985). Isolation and Aggregation in Economics. Berlin, Heidelberg: Springer Verlag. URL http://epub.ub.uni-muenchen.de/3/.

Schlicht, E. (2006). A Variant of Uzawa's Theorem. Economics Bulletin, 5(6): 1-5. URL http://EconPapers.repec.org/RePEc:ebl:ecbull:eb-o6e10oo1.

Sen, A. K. (1963). Neo-Classical and Neo-Keynesian Theories od Distribution. The Economic Record, 39(85): 53-64. URL http://EconPapers.repec.org/RePEc:bla: ecorec:v:39:y:1963:i:85:p:53-64.

Solow, R. M. (1956). A Contribution to the Theory of Economic Growth. The Quarterly Journal of Economics, 70(1): pp. 65-94. ISSN 00335533. URL http: //www.jstor.org/stable/1884513. 
Uzawa, H. (1961). Neutral Inventions and the Stability of Growth Equilibrium. Review of Economic Studies, 28(2): 117-24. URL http://www.jstor.org/stable/ 2295709.

Vogt, W. (1968). Kapitalakkumulation und technischer Fortschritt. Weltwirtschaftliches Archiv, 100: pp. 185-196. ISSN 00432636. URL http://www.jstor.org/stable/40436628.

von Weizsacker, C. C. (1971). Steady state capital theory. Springer-Verlag. URL http://amazon.com/o/ASIN/Boo7EUYRPS/.

von Weizsäcker, C. C. (1962/2010). A New Technical Progress Function (1962). German Economic Review, 11(3): 248-265. URL http://EconPapers.repec.org/ RePEc:bla:germec:v:11:y:2010:i::p:248-265.

von Weizsäcker, C. C. (1966). Income Distribution and Technical Progress in Equilibrium Growth. A Generalization of the Marginalist Approach. Zeitschrift für die gesamte Staatswissenschaft / Journal of Institutional and Theoretical Economics, 122(3): pp. 400-417. ISSN 00442550. URL http://www.jstor.org/stable/40748974.

von Weizsäcker, C. C. (1966a). Tentative Notes on a Two Sector Model with Induced Technical Progress. The Review of Economic Studies, 33(3): 245-251. IssN 00346527. URL http://www.jstor.org/stable/2974418.

von Weizsäcker, C. C. (1966b). Zur Okonomischen Theorie des Technischen Fortschritts. Gottingen, Vandenhoeck \& Ruprecht, 1st edition. URL http: //amazon.com/o/ASIN/Boo57oWMDG/.

\section{Appendix 1: Cost Minimization}

The model (13), (14) has been derived, mainly for analytical convenience, under the assumption that the choice of capital deepening maximizes the decline in unit costs at each point in time ("gradient cost minimization"). In the following the solution for cost minimization will be provided. It will turn out that gradient cost minimization and full cost minimization are equivalent in a steady state, but differ outside a steady state somewhat.

We start with the problem of minimizing unit costs at some future point in time by selecting an appropriate time-path of capital deepening. The problem 
has been originally posed (but not solved) by Samuelson $(1965,350)$ in his version of the Kennedy-Weizsäcker theory. For the hybrid model it can be solved by a straightforward variational argument.

Define the function $\phi$ that describes the Kennedy-Weizsäcker trade-off between the growth rates of productivities for capital $\hat{x}$ and labor $\hat{y}$ :

$$
\hat{y}=\phi(\hat{x}) .
$$

This frontier is implied by the identity $\hat{x}=\hat{y}-\hat{k}$ and the technical progress function $\hat{y}=\varphi(\hat{k})$ with $\gamma=\varphi(\gamma)$. The function is implicitly defined by

$$
\phi(\hat{x})=\varphi(\phi(\hat{x})-\hat{x})
$$

and has the properties

$$
\begin{aligned}
\phi(0) & =\gamma \\
\phi^{\prime} & =-\frac{\varphi^{\prime}}{1-\varphi^{\prime}} \in(-1,0) \\
\phi^{\prime \prime} & =\frac{\varphi^{\prime \prime}}{\left(1-\varphi^{\prime}\right)^{3}}<0 .
\end{aligned}
$$

Consider the problem to minimize unit costs at a future date $T>0$ when starting with labor productivity $y_{0}$ and capital productivity $x_{0}$ at time $t=0$. Wages grow along the steady state path according to

$$
w_{t}=w_{0} e^{\gamma t},
$$

the rate of interest $r$ remains constant over time, and initial unit costs are one:

$$
z_{0}=\frac{r+\delta}{x_{0}}+\frac{w_{0}}{y_{0}}=1 .
$$

The firm wants to minimize unit costs at some point in time $T>0$ by selecting suitable time-paths of the increases in productivity growth $\hat{x}$ and $\hat{y}$. As these timepaths are constrained by the trade-off ( $\left.\mathrm{A}_{1}\right)$, the problem reduces to selecting just a time path $\hat{x}_{t}$. This entails the time path $\hat{y}_{t}=\phi\left(\hat{x}_{t}\right)$ of labor productivity and the time path $\hat{k}_{t}=\hat{y}_{t}-\hat{x}_{t}$ of capital deepening. For ease of notation we denote the change in capital productivity by

$$
u_{t}=\hat{x}_{t}
$$

and take this as the control variable that is used to minimize costs at time $T$. 
Lemma. For any given $T>0$, an optimal control $u_{t}^{*}$ that minimizes unit costs at time $T$ over the set of piecewise continuous controls is a constant control.

Proof. With control $u_{t}$, the productivities at $t=T$ are given by

$$
\begin{aligned}
& x_{T}=x_{0} e^{\int_{0}^{T} u_{t} d t} \\
& y_{T}=y_{0} e^{\int_{0}^{T} \phi\left(u_{t}\right) d t}
\end{aligned}
$$

and the implied unit costs at time $T$ are

$$
z_{T}=\frac{r+\delta}{x_{0} e^{\int_{0}^{T} u_{t} d t}}+\frac{w_{0} e^{\gamma T}}{y_{0} e^{\int_{0}^{T} \phi\left(u_{t}\right) d t}} .
$$

Assume that $u_{t}^{*}$ is optimal and consider any other possible control. It differs from $u_{t}^{*}$ by

$$
\triangle_{t}=u_{t}-u_{t}^{*}
$$

We refer to $\Delta_{t}$ as a variation. Consider now the set of controls parametrized by $\varepsilon$ :

$$
\mathfrak{U}=\left\{u_{t}^{*}+\varepsilon \triangle_{t} \mid \varepsilon \in[-1,1]\right\} .
$$

This set contains all convex combinations of controls $u_{t}^{*}$ and $u_{t}$. In particular it contains $u_{t}^{*}($ for $\varepsilon=0)$ and $u_{t}($ for $\varepsilon=1)$. Given some control $u_{t}^{*}$ and any variation $\triangle_{t}$, the unit costs resulting from controls taken out of the set $\mathfrak{U}$ are a function of $\varepsilon$ :

$$
z_{T}(\varepsilon)=\frac{r+\delta}{x_{0}} e^{-\int_{0}^{T}\left(u_{t}^{*}+\varepsilon \triangle_{t}\right) d t}+\frac{w_{0}}{y_{0}} e^{-\int_{0}^{T} \phi\left(u_{t}^{*}+\varepsilon \triangle_{t}-\gamma\right) d t}
$$

The first derivative is

$$
\begin{aligned}
\frac{\partial z_{T}}{\partial \varepsilon} & =-\frac{r+\delta}{x_{0}} e^{-\int_{0}^{T}\left(u_{t}^{*}+\varepsilon \Delta_{t}\right) d t} \int_{0}^{T} \triangle_{t} d t-\frac{w_{0}}{y_{0}} e^{-\int_{0}^{T} \phi\left(u_{t}^{*}+\varepsilon \Delta_{t}-\gamma\right) d t} \int_{0}^{T} \phi^{\prime} \triangle_{t} d t \\
& =-\int_{0}^{T}\left(\frac{r+\delta}{x_{T}}+\frac{w_{T}}{y_{T}} \phi^{\prime}\left(u_{t}^{*}+\varepsilon \triangle_{t}\right)\right) \triangle_{t} d t
\end{aligned}
$$

The second derivative is strictly positive:

$$
\frac{\partial z_{T}^{2}}{\partial \varepsilon^{2}}=-\int_{0}^{T} \frac{w_{T}}{y_{T}} \phi^{\prime \prime}\left(u_{t}^{*}+\varepsilon \triangle_{t}\right) \triangle_{t}^{2} d t>0
$$


A necessary condition for a minimum is that the first derivative of $z_{t}$ vanishes at $\varepsilon=0$ :

$$
\left.\frac{\partial z_{T}}{\partial \varepsilon}\right|_{\varepsilon=0}=-\int_{0}^{T}\left(\frac{r+\delta}{x_{T}}+\phi^{\prime}\left(u_{t}^{*}\right)\right) \triangle_{t} d t=0
$$

Consider the possible variation

$$
\triangle_{t}=\frac{r+\delta}{x_{T}}+\phi^{\prime}\left(u_{t}^{*}\right)
$$

With this variation, the necessary condition for a minimum (A 15) reads

$$
\left.\frac{\partial z_{T}}{\partial \varepsilon}\right|_{\varepsilon=0}=-\int_{0}^{T}\left(\frac{r+\delta}{x_{T}}+\phi^{\prime}\left(u_{t}^{*}\right)\right)^{2} d t=0 .
$$

This implies $\phi^{\prime}\left(u_{t}^{*}\right)=-\frac{r+\delta}{x_{T}}$ for almost all $t \in[0, T]$ and hence that $u_{t}^{*}$ is the same for almost all $t$. Write this as

$$
u_{t}^{*}=\bar{u} \text { for almostall } t \in[0, T] .
$$

Proposition. Denote the initial profit share by $\pi_{0}=\frac{r+\delta}{x_{0}}$.

If $\pi_{0}=\varphi^{\prime}(\gamma)$, the optimal control is $u_{t}=\bar{u}=0$.

If $\pi_{0}>\varphi^{\prime}(\gamma)$, the optimal control is $u_{t}=\bar{u}>0$.

If $\pi_{0}<\varphi^{\prime}(\gamma)$, the optimal control is $u_{t}=\bar{u}<0$.

For $T$ sufficiently large, the optimal control is arbitrarily close to $u_{t}=\bar{u}=0$.

Proof. With

$$
\begin{aligned}
\frac{r+\delta}{x_{0}} & =\pi_{0} \\
\frac{w_{0}}{y_{0}} & =1-\pi_{0}
\end{aligned}
$$

and a constant $u_{t}=\bar{u}$ (as implied by the Lemma), we obtain from (A 11) unit costs at time $T$ as

$$
z_{T}=\pi_{0} e^{-\bar{u} T}+\left(1-\pi_{0}\right) e^{-(\phi(\bar{u})-\gamma) T} .
$$

This is to be minimized with respect to $\bar{u}$. The derivatives are

$$
\begin{aligned}
\frac{\partial z_{T}}{\partial \bar{u}}= & -T \pi_{0} e^{-\bar{u} T}-T\left(1-\pi_{0}\right) e^{-(\phi(\bar{u})-\gamma) T} \phi^{\prime}(\bar{u}) \\
\frac{\partial^{2} z_{T}}{\partial \bar{u}^{2}}= & T^{2} \pi_{0} e^{-\bar{u} T}+T^{2}\left(1-\pi_{0}\right) e^{-(\phi(\bar{u})-\gamma) T}\left(\phi^{\prime}(\bar{u})\right)^{2}+ \\
& -T\left(1-\pi_{0}\right) e^{-(\phi(\bar{u})-\gamma) T} \phi^{\prime \prime}(\bar{u}) .
\end{aligned}
$$


As all terms in (A 20) are strictly positive, any solution $\bar{u}$ to $\frac{\partial z_{T}}{\partial \bar{u}}=0$ gives a unique minimum of $z_{T}$.

At $\bar{u}=0$ we obtain

$$
\left.\frac{\partial z_{T}}{\partial \bar{u}}\right|_{\bar{u}=0}=-T \pi_{0}-T\left(1-\pi_{0}\right) \phi^{\prime}(0) .
$$

This implies

$$
\left.\frac{\partial z_{T}}{\partial \bar{u}}\right|_{\bar{u}=0} \gtreqless 0 \Leftrightarrow-\phi^{\prime}(0) \gtreqless \frac{\pi_{0}}{1-\pi_{0}}
$$

and implies for the cost-minimizing solution $\bar{u}^{*}$

$$
\bar{u}^{*} \gtreqless 0 \Leftrightarrow-\phi^{\prime}(0) \lesseqgtr \frac{\pi_{0}}{1-\pi_{0}} .
$$

As $-\phi^{\prime}=\frac{\varphi^{\prime}}{1-\varphi^{\prime}}$, this can be expressed in terms the technical progress function as

$$
\bar{u}^{*} \gtreqless 0 \Leftrightarrow \varphi^{\prime}(\gamma) \lesseqgtr \pi_{0} .
$$

If we start with the equilibrium profit share $\pi_{0}=\varphi^{\prime}(\gamma)$, it is optimal to continue with the rate of capital deepening $\gamma$. This will keep capital productivity constant and labor productivity growing at the rate $\gamma$. If we start with a profit share $\pi_{0}$ that exceeds $\gamma$, it is optimal to select a rate of capital deepening less than $\gamma$ that entails growing capital productivity and a growth in labor productivity less than $\gamma$. Conversely an initial profit share $\pi_{0}<\varphi^{\prime}(\gamma)$ would require a rate of capital deepening exceeding $\gamma$. All this is qualitatively similar to gradient cost minimization, but the reaction will be much less pronounced.

To see this, consider the first-order condition for the minimizing solution $\bar{u}^{*}$ more closely. It can be written as

$$
\pi_{0} e^{\left(\phi\left(\bar{u}^{*}\right)-\gamma-\bar{u}^{*}\right) T}+\left(1-\pi_{0}\right) \phi^{\prime}\left(\bar{u}^{*}\right)=0 .
$$

This gives $\bar{u}^{*}$ implicitly as a function of $\pi_{0}$ and $T$. The partial derivatives of this function are

$$
\begin{aligned}
& \frac{\partial \bar{u}^{*}}{\partial \pi_{0}}=-\frac{e^{\left(\phi\left(\bar{u}^{*}\right)-\gamma-\bar{u}^{*}\right) T}-\phi^{\prime}\left(\bar{u}^{*}\right)}{T \pi_{0} e^{\left(\phi\left(\bar{u}^{*}\right)-\gamma-\bar{u}^{*}\right) T}\left(\phi^{\prime}-1\right)+\left(1-\pi_{0}\right) \phi^{\prime \prime}\left(\bar{u}^{*}\right)} \\
& \frac{\partial \bar{u}^{*}}{\partial T}=-\frac{\left(\phi\left(\bar{u}^{*}\right)-\gamma-\bar{u}^{*}\right) e^{\left(\phi\left(\bar{u}^{*}\right)-\gamma-\bar{u}^{*}\right) T}}{T \pi_{0} e^{\left(\phi\left(\bar{u}^{*}\right)-\gamma-\bar{u}^{*}\right) T}\left(\phi^{\prime}-1\right)+\left(1-\pi_{0}\right) \phi^{\prime \prime}\left(\bar{u}^{*}\right)}
\end{aligned}
$$


As the denominator in both expressions is strictly negative we have

$$
\begin{aligned}
& \frac{\partial \bar{u}^{*}}{\partial \pi_{0}}>0 \\
& \frac{\partial \bar{u}^{*}}{\partial T} \gtreqless 0 \Leftrightarrow \bar{u}^{*} \lesseqgtr 0 .
\end{aligned}
$$

Therefore a higher initial profit share leads to a higher increase in capital productivity. This goes along with smaller rate of capital deepening. Conversely a smaller share of profits leads to a higher rate of capital deepening. The larger the planning horizon $T$, the less pronounced will be this reaction.

From (A 21) we see further that for $T \rightarrow \infty$, the expression $\left(\phi\left(\bar{u}^{*}\right)-\gamma-\bar{u}^{*}\right)$ must go to zero, because $\left(\phi\left(\bar{u}^{*}\right)-\gamma-\bar{u}^{*}\right) T$ must remain bounded and we conclude that the optimal control $\bar{u}^{*}$ must go to zero:

$$
\lim _{T \rightarrow \infty} \bar{u}^{*}=0 .
$$

In other words: If the firm wants to minimize costs in the very distant future, it will select a rate of capital deepening very close to the equilibrium rate $\gamma$.

Hence gradient cost minimization used in Section 2.3 is only optimal in the steady state. Outside the steady state it is optimal to react to differences between the profit share and the slope of the technical progress function $\varphi^{\prime}(\gamma)$ in a less pronounced, but qualitatively similar way. This qualitative result carries over to the minimization of the present value of total costs, as this involves minimization of a weighted average of future costs.

\section{Appendix 2: Convergence in the Neoclassical Twin}

In the following, the relative convergence of different solutions to the differential equation (18) describing the neoclassical twin is shown. The function $f$ is assumed to satisfy the Inada conditions, and $\psi$ inherits them: $\psi(0)=0, \psi^{\prime}>0, \psi^{\prime \prime}<0$, $\psi^{\prime}(0)=\infty, \psi^{\prime}(0)=\infty, \psi^{\prime}(\infty)=0$. This implies that for $\frac{1}{s}(v+\delta+\gamma)>0$ the equation

$$
\psi\left(\bar{k}_{0}\right)=\frac{1}{s}(v+\delta+\gamma) \bar{k}_{0}
$$


has a positive root $\bar{k}_{0}$ that is unique, and that $\frac{\psi(\xi)}{\xi}$ is a decreasing function of $\xi$. Hence the expression $\left(\log \xi-\log \bar{k}_{0}\right)\left(\frac{\psi(\xi)}{\xi}-\frac{\psi\left(\bar{k}_{0}\right)}{\bar{k}_{0}}\right)$ is negative definite:

$$
\left(\log \xi-\log \bar{k}_{0}\right)\left(\frac{\psi(\xi)}{\xi}-\frac{\psi\left(\bar{k}_{0}\right)}{\bar{k}_{0}}\right)<0 \text { for all } \xi>0 \text { with } \xi \neq \bar{k}_{0} \text {. }
$$

It is easy to check that the time-path

$$
\bar{k}_{t}=e^{\gamma t} \bar{k}_{0}
$$

satisfies (18).

Define

$$
\xi_{t}=e^{-\gamma t} k_{t}
$$

Equations (18) and (A 22) imply

$$
\dot{\xi}_{t}=s \psi\left(\xi_{t}\right)-(v+\delta+\gamma) \xi_{t} .
$$

Consider now the relative distance between any solution $k_{t}$ of (18) and $\bar{k}_{t}$ :

$$
V_{t}=\left(\log k_{t}-\log \bar{k}_{t}\right)^{2}
$$

As $k_{t}=e^{\gamma t} \xi_{t}$ and $\bar{k}_{t}=e^{\gamma t} \bar{k}_{0}$, this is identical to

$$
V_{t}=\left(\log \xi_{t}-\log \bar{k}_{0}\right)^{2} .
$$

The time derivative of this distance is

$$
\begin{aligned}
\dot{V}_{t} & =2\left(\log \xi_{t}-\log \bar{k}_{0}\right) \hat{\xi}_{t} \\
& =2 s\left(\log \xi_{t}-\log \bar{k}_{0}\right)\left(\frac{\psi\left(\xi_{t}\right)}{\xi_{t}}-\frac{(v+\delta+\gamma)}{s}\right) .
\end{aligned}
$$

Equation (A 22) implies $\frac{(v+\delta+\gamma)}{s}=\psi\left(\bar{k}_{0}\right)$ and we can write

$$
\dot{V}_{t}=2 s\left(\log \xi_{t}-\log \bar{k}_{0}\right)\left(\frac{\psi\left(\xi_{t}\right)}{\xi_{t}}-\frac{\psi\left(\bar{k}_{0}\right)}{\bar{k}_{0}}\right)
$$

which is negative whenever $\xi_{t}$ differs from $\bar{k}_{0}$, see (A 23). Hence all solutions of (18) converge in the sense that the ratio of two solutions $k_{t}^{\prime}$ and $k_{t}^{\prime \prime}$ approach unity. (This does not imply that the distance between such solutions shrinks over time.) 